\title{
Determinants of Academics' Knowledge Sharing Behavior in United Arab Emirates Universities
}

\author{
${ }^{*}$ Roslina Othman, Huda Skaik \\ International Islamic University Malaysia \\ *roslina@iium.edu.my
}

\begin{abstract}
This research aims to determine the factors affecting knowledge sharing behavior among academics in United Arab Emirates universities and identify the effect of university type on academics' behavior. The research adopted Ajzen's amended Theory of Planned Behavior. Employing an online survey, data were collected from academics in public and private universities using a questionnaire. The model was tested using Partial Least Squares structural equation modeling. The results found a significant difference in academics' knowledge sharing behavior between public and private universities. Results also revealed that intention is the main determinant of knowledge sharing behavior, and that attitude, subjective norms, and self-efficacy have significant influence on intention while controllability has no influence on it. The significance of this research lies in that it is one of the first to use the amended theory and the only research to address knowledge sharing behavior in higher education in the Arab World. This research provides useful basis for higher education institutions to create a knowledge sharing culture and helps academics to enhance their performance.
\end{abstract}

Keywords: knowledge sharing behavior, theory of planned behavior, United Arab Emirates, academics, universities

\section{Introduction}

Knowledge sharing is one of the major processes of knowledge management (Nonaka \& Takeuchi, 1995) and the key to organizational and individual development (Alavi \& Leidner, 2001). It is the process of exchanging and transferring existing knowledge and ideas among people in order to create new knowledge and ideas (Syed, Zaini, Noormala \& Zahariah, 2009). There are numerous benefits for knowledge sharing on both organizational and individual levels. On the organizational level, it helps in achieving continuous organizational growth and long term sustainability and success (Ling, Sandhu \& Kamal, 2009; Nonaka \& Takeuchi, 1995; Sandhawalia \& Dalcher, 2011), meeting organization's goals and objectives, solving business problems (Riege, 2005; Wang \& Noe, 2010), enhancing market performance, maintaining competitiveness and profitability (Hsu, 2008; Riege, 2005), gaining better understanding of customer needs (Sandhawalia \& Dalcher, 2011). On the individual level, it helps in promoting individuals' learning and innovation (Egger, 2013; Ling et al., 2009), enhancing their performance (Srivastava, Bartol \& Locke, 2006; Xiao \& Jin, 2010), skills and competencies (Ketvirtis, 2011), transferring knowledge among each other in the same unit or from one to another (Riege, 2005), and strengthening individuals' capabilities (Egger, 2013). In the knowledge-based age, universities seek to ensure success and permanence, achieve organizational goals (Sharma, 2010), and have constant performance improvements. In the academic environment, the role of knowledge sharing is becoming quite significant to achieve maximum results for academic institutions (Babalhaveji \& Kermani, 2011) due to the important role academics play in providing education, conducting research, and publishing scholarly works. In addition to the Universities responsibility, as knowledge-based environments, for creating, managing, exchanging, and disseminating knowledge within societies. Therefore, universities should promote knowledge sharing among their academics.

\section{Literature Review}

Knowledge Sharing in Higher Education: Universities are knowledge-intensive environments and are responsible for creating, managing, and disseminating knowledge in society. They are science centers established to generate and provide knowledge, and to equip people with the best education in order to serve their societies. They grow and prosper from the knowledge of their academics, staff, and students (Singer \& Hurley, 2005). Accordingly to ensure success, achieve their goals (Sharma, 2010), and have constant performance improvements, universities should promote knowledge sharing among their 
academics. In today's knowledge-based age, the importance of education is increasing gin advancing science and technology, spreading information and knowledge, and promoting literacy. During the $19^{\text {th }}$ and $20^{\text {th }}$ centuries, the development of education was a critical driver for building societies (Mazzarol \& Soutar, 2002). Meanwhile in the twenty first century, the role of education became critical for the development of knowledge-based societies, where individuals are responsible for their own development (Sallis \& Jones, 2002). Such development will only be accomplished with the sharing of individuals' knowledge. However, research-based knowledge has not been very successful in guiding decision makers in universities to value their capital assets and to manage and utilize the knowledge of these assets (Gera, 2012). Moreover, while there are broad researches about knowledge management and its processes in different areas, research about knowledge sharing in higher education is scarce (Fullwood, Rowley \& Delbridge, 2013). Knowledge sharing is an essential concept in universities (Sohail \& Daud, 2009), where knowledge creation, management, sharing, and utilization is implanted (Cheng, Ho \& Lau, 2009). According to Cheng et al. (2009), the impact of knowledge sharing in higher education institutions could be larger than that created by business organizations. They further indicate that implementing knowledge sharing properly and wisely can create a competitive advantage for all kinds of higher education institutions.

In academic environment, the role of knowledge sharing is quite significant to achieve maximum results (Babalhavaeji \& Kermani, 2011) considering the important role of academics in education, research, and scholarly work. The process of knowledge sharing is gaining more attention by many researchers because knowledge sharing is relevant to the critical role of higher education institutions where knowledge is being created (Aulawi, Sudirman, Suryadi \& Govindaraju, 2009; Babalhavaeji \& Kermani, 2011; Kamal, Singh \& Kaur, 2007; Patel \& Ragsdell, 2011; Sohail \& Daud, 2009). According to Sallis and Jones (2002), academics are expert knowledge workers engaged in teaching, writing, and research, and their academic institutions generate value using their intellectual assets. For academics in particular, to share knowledge is part of their daily job and work activities. They create, manage, disseminate, and share knowledge with each other and with students (Sohail \& Daud, 2009). Moreover, the knowledge created, stored, and shared serve as repository knowledge for academics, researchers, and students to distinguish the academic institution and to enhance their own knowledge and help them advance in their careers (Basu \& Sengupta, 2007). Therefore, realizing the importance of knowledge sharing for academics in terms of promoting their learning and innovation (Reige, 2005) will certainly encourage them to practice it. Despite the increasing awareness during the last few years of knowledge sharing benefits and the growing number of organizations adopting its strategies, almost none are in the higher education sector (Sallis \& Jones, 2002; Metcalf, 2006). There is a huge need for knowledge sharing in higher education as much as it is in business. If excellent achievements are achieved in one area of a university, there would be a process for knowing how they were achieved and there would be strategies to replicate them elsewhere. Realizing that human knowledge is doubling every 13 months on average (Schilling, 2013) definitely calls for developing knowledge sharing strategies in higher education institutions.

Knowledge Sharing in United Arab Emirates: In the last few years, the United Arab Emirates (UAE) has experienced significant local and foreign investments in various fields such as construction, infrastructure, telecommunications, media, information technology, hospitality and tourism (Ahmad \& Daghfous, 2010) as well as education, which is witnessing heavy investment at all levels (Boumarafi, 2006). In view of the government's commitment to invest in human capital and maintain the best possible quality of education, it has allocated more than $1 / 3$ of its budget to education and has allocated considerable funds to invest in research (Al Nahyan, 2012). The government also announced a strategy in 2010 to invest in its human capital and establish a knowledge-based society with a knowledge-based economy (Al Nahyan, 2012). Thus, the government collaborated with numerous academic institutes from around the world to establish campuses in UAE in order to contribute in raising the standards of the higher education in UAE (Al Nahyan, 2012). One of the major initiatives towards establishing a knowledge-based society in the region was the establishment 'Mohammed Bin Rashid Al Maktoum Foundation' to promote knowledge in the region. H.H. Sheikh Muhammad, Ruler of Dubai, has stated, "There is a need to build an Arab model of knowledge that reflects Arab culture" (Mirghani, O'Sullivan \& Ribiere, 2008, p. 111). He also indicated that such a model will definitely develop the human capabilities, provide skilled regional leaders, meet the needs of economic, social, and cultural development in the Arab world, protect intellectuals, researchers, and inventors, as well as keep pace with the international standards in production, quality, and performance. 
A number of papers have been published about knowledge sharing in UAE in particular, where the authors addressed knowledge sharing in business and management (Ahmad \& Daghfous, 2010), police force service (Rowley, Seba \& Delbridge, 2012; Seba, Rowley \& Lambert, 2012), and construction (Skok \& Tahir, 2010). The authors studied the practice of knowledge sharing and its activities, in addition to the influence of some organizational, individual, and technological factors on it. However, there have not been any studies addressing knowledge sharing in the higher education sector. If UAE is to play its aspired role in creating knowledge and establishing a knowledge-based society in the region, the government has to promote a culture of knowledge sharing (Alrawi \& Jaber, 2007) particularly within academic institutions given their importance in knowledge creation and dissemination. Therefore, this research intends to understand academics' knowledge sharing behavior in United Arab Emirates universities and evaluate the influence of some factors on it. It also identifies the effect of the type of university on the academics' knowledge sharing behavior. The significance of this research lies in the fact that it is the first to address knowledge sharing in higher education sector in UAE with particular emphasis on academics' knowledge sharing behavior considering their important role in creating knowledge and the importance of knowledge sharing in achieving universities' goals.

\section{Research Questions}

- Is there any significant difference between academics' knowledge sharing behavior in public and private universities?

- What are the determinants influencing academics' actual knowledge sharing behavior based on the TPB?

i) Does intention towards knowledge sharing influence the academics' actual knowledge sharing behavior?

ii) Does attitude towards knowledge sharing influence the academics' intention to share knowledge?

iii) Does subjective norm towards knowledge sharing influence the academics' intention to share knowledge?

iv) Does self-efficacy towards knowledge sharing influence the academics' intention to share knowledge?

v) Does controllability towards knowledge sharing influence the academics' intention to share knowledge?

\section{Theoretical Framework}

The Theory of Planned Behavior (TPB): The study adopted Ajzen's new model of Theory of Planned Behavior (2002), which provided a framework to study the academics' knowledge sharing behavior. TPB has emerged as one of the most influential and popular conceptual frameworks to study individuals' behavioral intentions and actual behaviors (Lin \& Lee 2004). According to TPB (1985), human behavior is guided by three kinds of salient beliefs: behavioral beliefs about the likely consequences or attributes of the behavior, normative beliefs about the normative expectations of other people, and control beliefs about the presence of factors that may facilitate or hinder performance of the behavior. In their respective aggregates, behavioral beliefs produce a favorable or unfavorable attitude toward the behavior; normative beliefs result in perceived social pressure or subjective norms; and control beliefs give rise to perceived behavioral control, the perceived ease or difficulty of performing the behavior. In combination, attitude, subjective norms, and perceived behavioral control lead to the formation of a behavioral intention. However, due to all the conceptual and methodological ambiguities concerning the concept of perceived behavioral control, Ajzen $(1991,2002)$ stated that perceived behavioral control should be viewed as two interrelated components, which he identified as self-efficacy and controllability. According to Ajzen (2006), the more favorable the attitude and subjective norm, and the greater the selfefficacy and controllability, the stronger should be the individual's intention to carry out the behavior. Intention itself is regarded as the immediate antecedent of behavior.

Theoretical and Empirical Background: Behavior is the degree to which an individual actually decides to perform or not perform a specific action and it is determined by the individual's intention to perform it or not (Ajzen, 1991; Ajzen \& Fishbein, 1980). Robertson (2002) states that knowledge sharing is a human action. Therefore, knowledge sharing behavior itself is an individual's optional behavior, not directly recognized, and in the collective supports effective functioning of an organization's operations and performance (Bordia, Irmer, Garden, Phair \& Abusah, 2004). Consequently, according to TPB, within the context of the current study, an academic's knowledge sharing behavior is the degree to which an 
academic actually shares his/her knowledge with others. Intention is an individual's willingness to engage in certain behavior (Ajzen, 1985, 1991, 2002) and it is the most significant predictor and central factor influencing behavior (Ajzen \& Fishbein, 1980; Ajzen, 1991). Based upon TPB, intention to share knowledge is the individual's willingness and readiness to engage in knowledge sharing behavior. Thus, an individual's intention to share knowledge highly determines his/her actual behavior to share knowledge (Alajmi, 2011). In knowledge sharing context, researchers found that intention directly and significantly affects individual's knowledge sharing behavior (Alajmi, 2011, 2010; Babalhavaeji \& Kermani, 2011; Chen, Chen \& Kinshuk, 2009; Ellahi \& Mushtaq, 2011; He-feng, 2009; Keyes, 2008; Lin \& Lee, 2004; Tohidinia \& Mosakhani, 2010).

Attitude is the degree to which an individual has favorable or unfavorable evaluation of the behavior (Ajzen, 1991). Attitude towards the behavior is an influential factor to perform that behavior (Ajzen \& Fishbein, 1980; Ajzen, 1985, 1991, 2002) only indirectly by influencing the individual's intention, which is more closely linked to the behavior in question (Ajzen, 1991). With regard to knowledge sharing, attitude determines the individual's intention to perform knowledge sharing behavior (Alajmi, 2010). Therefore, the more favorable the individual's attitude toward sharing knowledge, the stronger his/her intention to share knowledge. Researches (Bock \& Kim, 2002; Bock, Zmud, Kim \& Lee, 2005; Ellahi \& Mushtaq, 2011; Hung, Lai \& Chou, 2010; Lin, 2007; Ryu, Ho \& Han, 2003; Tohidinia \& Mosakhani, 2010) have demonstrated a significant positive relationship between attitude and intention to share knowledge. Subjective norms are defined as the individual's perceived social pressure to perform or not to perform a given behavior (Ajzen, 1991). Thus, subjective norms refer to the individual's belief that important relevant others, including executive board, senior management, supervisor, and the peer group, expect $\mathrm{him} /$ her to engage in the behavior of interest (Chennamaneni, 2006). In terms of knowledge sharing, subjective norms refer to how the individual perceives others' view of sharing the knowledge. Thus, the stronger the individual's perceived subjective norms, the stronger his/her intention to share knowledge. Researches (Alajmi, 2010; Bock et al., 2005; Chen et al., 2009; He-feng, 2009; Hung et al., 2010; Lin \& Lee, 2004; Ryu et al., 2003; Tohidinia \& Mosakhani, 2010) proved that subjective norms is a significant determinant of individual's intention to share knowledge.

Self-efficacy is an individual's confidence in the ease or difficulty to perform the behavior in question (Ajzen, 2002), and is considered an important factor influencing an individual's intention to perform the behaviour (Ajzen, 1991, 2002). In terms of knowledge sharing, self-efficacy is an individual's estimate of how easy or difficult it is for him/her to share knowledge with others. According to Constant, Kiesler and Sproull (1994) an individual with high self-efficacy is more confident to share knowledge with others. Thus, the greater the individual's self-efficacy, the stronger his/her intention to share knowledge. Moreover, researchers (Bock \& Kim, 2002; Moshabbaki \& Jaha'nyan, 2009; Taylor \& Todd, 1995 in Lin \& Lee, 2004; Wasko \& Faraj, 2005; Ye, Chen \& Jin, 2006) found that self-efficacy significantly motivates an individual's intention to share knowledge. Controllability is an individual's beliefs, based on the available resources, about the extent to which performing a given behavior is up to him/her (Ajzen, 2002). Controllability is an important determinant that influences an individual's behavior through intention (Madden, Ellen \& Ajzen, 1992). In knowledge sharing, controllability is referred to as an individual's beliefs, based on the available resources, about the extent to which performing knowledge sharing behavior is up to him/her (Ajzen, 2002). Thus, the greater the individual's level of control over his/her knowledge sharing capabilities, the stronger his/her intention is to share knowledge. Researchers found that controllability is a significant determinant in influencing individual's intention to share knowledge (Chennamaneni, 2006; Hung et al., 2010; Kraft, Rise, Sutton \& Roysamb, 2005; So \& Bollju, 2005; Tavousi, Hidarnia, Montazeri, Hijizadeh, Taremain\& Ghofranipour, 2009; Trafimow, Sheeran, Conner \& FInaly, 2002).

Research Model and Hypotheses: The purpose of this study is to identify the factors influencing knowledge sharing behavior among academics in UAE universities applying the TPB model. Based on the theoretical framework and the past researches employing the TBP as indicated in the literature review, the current study is examining the influence of intention on knowledge sharing behavior as its main determinant, as well as the influence of attitude, subjective norms, self-efficacy, and controllability on intention as its predictors. Based on the theoretical and empirical background on the factors influencing knowledge sharing behavior, the following research model (Figure 1) and hypotheses are proposed:

H1: Intention to share knowledge has a significant effect on academics' knowledge sharing behavior

H2: Attitude has a significant effect on academics' intention to share knowledge 
H3: Subjective norms has a significant effect on academics' intention to share knowledge

H4: Self-efficacy has a significant effect on academics' intention to share knowledge

H5: Controllability has a significant effect on academics' intention to share knowledge

Figure 1: Research Model

\section{Methodology}

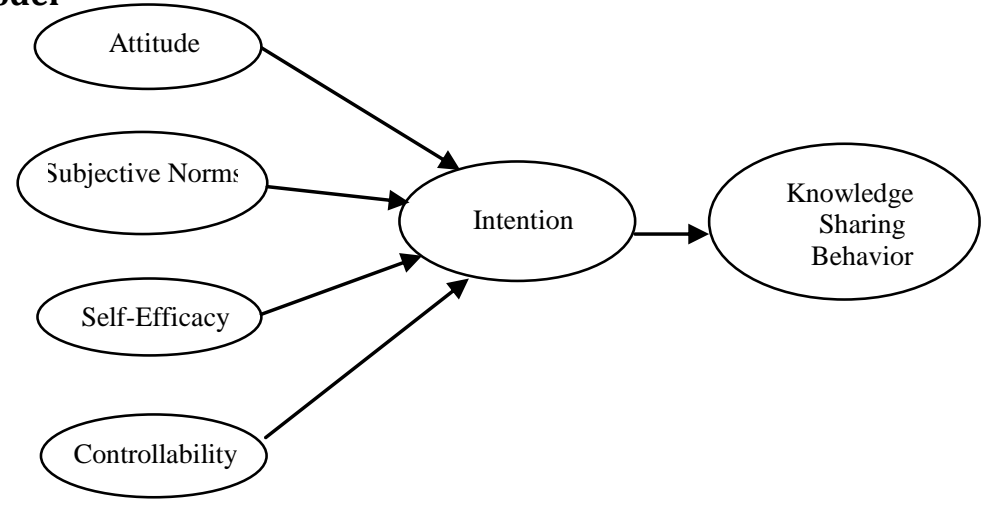

A cross-sectional web-based survey was used as a method to collect data from the academics working in public and private universities in UAE. The instrument employed for this purpose was questionnaire. The researchers have chosen universities as a setting for the research due to the excellent and diversified system of higher education that UAE has established and because UAE has become a home to wide range of public, private, local, and international universities. The sample for this study consisted of 85 academics working in different faculties in the surveyed universities. The sampling technique used for this study was the convenience sampling, which includes samples of whoever would be available at the time of conducting the research (Gay \& Airasian, 2003). Knowing that often the academics are reluctant to participate in research studies due to their tight schedule and lack of available time, the researchers have decided to choose the convenience sampling. The measurement items used in the questionnaire were developed and validated based upon Ajzen's theory of planned behavior (2006), and previous researches on knowledge sharing behavior including Bock et al. (2005), Chen et al. (2009), Hsu, Ju, Yen \& Chang (2007), Ryu et al. (2003), and Tohidinia and Mosakhani (2010). All items were measured using five-point Likert-scale.

The survey was conducted online by sending an email with URL links of the questionnaire to the participants in both English and Arabic, where they can answer and submit online. Following, the data were transferred later into SPSS to conduct the required analysis. Using SPSS 19.0, the sample descriptive characteristics were assessed based on the demographic information. The research model and research hypotheses were tested using partial least square path modeling (SmartPLS2.0 M3) (Hansmann \& Ringle, 2004). PLS path modeling is one of the statistical methods for structural equation modeling (SEM). It is a modeling procedure that performs path-analytics modeling with latent variables. Then, it simultaneously evaluates the measurement model and structural model relating the associated constructs (Kijsanayotin et al., 2009). The PLS method allows for more flexibility in modeling, and is able to provide solid results in the case of small samples (Abdi, 2003).

\section{Data Analysis and Results}

Demographics of Respondents: Table 1 shows the demographic information of the respondents.

Types of Universities and Knowledge Sharing Behavior: In order to know if there is any significant difference between academics' knowledge sharing behavior working in the public and private universities, an independent sample t-test was conducted. Table 2 shows the mean and st. deviation values for the two groups, while table 3 shows the results of the independent sample t-test. There was a significant difference in the knowledge sharing behavior for academics in public universities $[M=14.68$, $\mathrm{SD}=2.95]$ and academics in private universities $[\mathrm{M}=16.30, \mathrm{SD}=1.97]$ where $\mathrm{t}$-value $=-2.5$ and $\mathrm{p}$-value $=$ 0.02 which is less than 0.05 .

Table 1: Respondents' Demographic Information 


\begin{tabular}{|c|c|c|c|c|}
\hline Profile & & Category & Frequency & Percentage (\%) \\
\hline \multirow[t]{2}{*}{ Gender } & & Male & 60 & 70.6 \\
\hline & & Female & 25 & 29.4 \\
\hline \multirow[t]{4}{*}{ Age } & & $22-30$ & 2 & 2.4 \\
\hline & & $31-40$ & 26 & 30.6 \\
\hline & & $41-50$ & 29 & 34.1 \\
\hline & & 51 and above & 28 & 32.9 \\
\hline \multirow[t]{3}{*}{ Nationality } & & Local & 3 & 3.5 \\
\hline & & Middle Eastern & 17 & 20 \\
\hline & & International & 65 & 76.5 \\
\hline Level & of & Bachelor & 2 & 2.4 \\
\hline \multirow{3}{*}{ Education } & & Master & 29 & 34.1 \\
\hline & & Ph.D & 46 & 54.1 \\
\hline & & Other & 8 & 9.4 \\
\hline Type & of & Public & 72 & 84.7 \\
\hline University & & Private & 13 & 15.3 \\
\hline \multirow[t]{12}{*}{ Faculty } & & Agriculture & 1 & 1.2 \\
\hline & & Arts & 3 & 3.5 \\
\hline & & Business and Economics & 8 & 9.4 \\
\hline & & Communication and Media & 3 & 3.5 \\
\hline & & Education & 11 & 12.9 \\
\hline & & Engineering & 5 & 5.9 \\
\hline & & Humanities and Social Sciences & 10 & 11.8 \\
\hline & & IT & 5 & 5.9 \\
\hline & & Law & 1 & 1.2 \\
\hline & & Health Sciences & 15 & 17.6 \\
\hline & & Sciences & 10 & 11.8 \\
\hline & & Other & 13 & 15.3 \\
\hline \multirow[t]{6}{*}{ Position } & & Professor & 12 & 14.1 \\
\hline & & Associate Professor & 13 & 15.3 \\
\hline & & Assistant Professor & 25 & 29.4 \\
\hline & & Instructor & 20 & 23.5 \\
\hline & & Lecturer & 13 & 15.3 \\
\hline & & Other & 2 & 2.4 \\
\hline Years & of & $0-5$ & 13 & 15.3 \\
\hline \multirow[t]{4}{*}{ experience } & & $6-10$ & 20 & 23.5 \\
\hline & & $11-15$ & 19 & 22.4 \\
\hline & & $16-20$ & 9 & 10.6 \\
\hline & & 21 and above & 24 & 28.2 \\
\hline
\end{tabular}

Table 2: Group Statistics

\begin{tabular}{lllllc}
\hline & Type of university & N & Mean & \multicolumn{2}{l}{ Std. DeviationStd. Error Mean } \\
\hline knowledge sharing behavior & Public & 72 & 14.6806 & 2.95423 & .34816 \\
& Private & 13 & 16.3077 & 1.97419 & .54754 \\
\hline
\end{tabular}

Table 3: Independent Sample T-test

\begin{tabular}{lcllllll}
\hline & & \multicolumn{3}{c}{ Levene's } & \multicolumn{3}{c}{ Test fort-test for Equality of Means } \\
& & Equality of Variances & & \\
& F & Sig. & t & df & Sig. (2-tailed) \\
\hline $\begin{array}{llllll}\text { knowledge } \\
\text { behavior }\end{array}$ & $\begin{array}{l}\text { sharingEqual variances assumed } \\
\text { Equal variances not assumed }\end{array}$ & 4.173 & .044 & -1.906 & 83 & .060 \\
\hline
\end{tabular}

Assessment of Measurement Model: The purpose of assessing the measurement model is to test its reliability and validity. The assessing is done through examining the following: (a) indicator reliability by measuring the factor loadings of each of the manifest variables, which should be above 0.4 , (b) internal consistency reliability by measuring composite reliability and Cronbach's alpha which should be 0.7, (c) convergent validity by measuring the AVE, which should be more than 0.5 , and (d) discriminant validity by using Fornell-Larcker's criterion where the square root of the AVE for each construct exceeds the correlations between the construct and all other constructs (Hair et al., 2011). As shown in table 4, all 
factor loadings exceeded the recommended threshold value of 0.4 ranging from 0.775 to 0.949 . Composite reliability and Cronbach's alpha values varied from .846 for the variable 'knowledge sharing behavior' to .951 for the variable 'controllability'. Convergent validity was adequate where AVE values exceeded the recommended value of 0.5 . The discriminant validity was satisfactory where the square root of the constructs AVE values exceeded the correlations between the constructs and all indicators loaded higher on their own constructs.

Table 4: Results of Measurement Model Assessment

\begin{tabular}{|c|c|c|c|c|c|c|}
\hline Constructs & Items & $\begin{array}{l}\text { Factor } \\
\text { Loading }\end{array}$ & $\begin{array}{l}\text { Composite } \\
\text { Reliability }\end{array}$ & $\begin{array}{l}\text { Cronbach's } \\
\text { Alpha }\end{array}$ & AVE & $\sqrt{A V E}$ \\
\hline \multirow{4}{*}{$\begin{array}{l}\text { Knowledge } \\
\text { Behavior }\end{array}$} & KSB1 & 0.869 & 0.8989 & 0.846 & 0.6905 & 0.831 \\
\hline & KSB2 & 0.856 & & & & \\
\hline & KSB4 & 0.801 & & & & \\
\hline & KSB5 & 0.798 & & & & \\
\hline \multirow[t]{5}{*}{ Intention } & INT1 & 0.822 & 0.9275 & 0.902 & 0.7193 & 0.848 \\
\hline & INT2 & 0.884 & & & & \\
\hline & INT3 & 0.828 & & & & \\
\hline & INT4 & 0.861 & & & & \\
\hline & INT5 & 0.846 & & & & \\
\hline \multirow[t]{5}{*}{ Attitude } & ATT1 & 0.901 & 0.9549 & 0.939 & 0.8093 & 0.900 \\
\hline & ATT2 & 0.905 & & & & \\
\hline & ATT3 & 0.877 & & & & \\
\hline & ATT4 & 0.909 & & & & \\
\hline & ATT5 & 0.907 & & & & \\
\hline \multirow[t]{5}{*}{ Subjective Norms } & SN1 & 0.877 & 0.9187 & 0.888 & 0.6936 & 0.833 \\
\hline & SN2 & 0.879 & & & & \\
\hline & SN3 & 0.810 & & & & \\
\hline & SN4 & 0.861 & & & & \\
\hline & SN5 & 0.775 & & & & \\
\hline \multirow[t]{5}{*}{ Self Efficacy } & SE1 & 0.912 & 0.9568 & 0.941 & 0.8160 & 0.903 \\
\hline & SE2 & 0.878 & & & & \\
\hline & SE3 & 0.902 & & & & \\
\hline & SE4 & 0.925 & & & & \\
\hline & SE5 & 0.899 & & & & \\
\hline \multirow{5}{*}{ Controllability } & CON1 & 0.925 & 0.9624 & 0.951 & 0.8369 & 0.915 \\
\hline & CON2 & 0.928 & & & & \\
\hline & CON3 & 0.949 & & & & \\
\hline & CON4 & 0.894 & & & & \\
\hline & CON5 & 0.878 & & & & \\
\hline
\end{tabular}

Assessment of Structural Model: The purpose of assessing the structural model is to evaluate its validity and test the hypotheses. The assessment of the structural model included examining the coefficient of determination $\mathrm{R}^{2}$, path coefficients, and the t-statistics to assess the significance of these path coefficients (Hair et al., 2011). The results of analyzing the structural model demonstrated an adequate and valid model. The $\mathrm{R}^{2}$ values for knowledge sharing behavior and intention were large demonstrating strong explanatory power. The path coefficients demonstrated significant levels that exceeded the recommended $\beta$ value of 0.1 at $t$-statistics values of 1.96 and 2.59. Figure 2 shows the structural model as produced by SmartPLS 2.0, the path coefficients, $\mathrm{R}^{2}$, and factor loadings.

Hypothesis Testing: For testing the study hypotheses, both path estimates and t-statistics were evaluated. Path coefficients were examined using PLS algorithm test, and t-statistics were examined using bootstrapping test. The bootstrapping test is basically a re-sample using the available observations as a basis (Rijlaarsdam, 2007) and it results in a larger sample, which is claimed to model the unknown population (Henderson 2005). The method is useful in experimental settings with small and medium sample sizes (Kenett et al., 2006). In accordance with Chin's (1998) recommendation, a bootstrapping procedure using 200 sub-samples was performed. Table 5 shows the results of the test. Significant $t-$ values for a two-tailed test are 1.65, 1.96, and 2.59 at p-values $0.1,0.05$, and 0.01 respectively (Hair, Ringle \& Sarstedt, 2011). 




Table 5: Results of Hypotheses Testing

\begin{tabular}{lllll}
\hline Hypotheses & Relationship & Path Coefficient & T-statistics & Conclusion \\
\hline H1 & INT $\rightarrow$ KSB & 0.518 & 7.170 & supported \\
H2 & ATT $\rightarrow$ INT & 0.338 & 4.752 & supported \\
H3 & SN $\rightarrow$ INT & 0.314 & 3.169 & supported \\
H4 & SE $\rightarrow$ INT & 0.276 & 2.056 & supported \\
H5 & CON $\rightarrow$ INT & -0.139 & 1.421 & Not supported \\
\hline
\end{tabular}

Discussion: In order to identify the difference in knowledge sharing behavior between academics working in public universities and those working in private universities, the research found a significant difference in academics' knowledge sharing behavior between public and private universities. Probably the difference in the results reflects a difference in the policies and rules between the public and private universities. Moreover, it may reflect the existence of some factors - individual, organizational, or technological - that affects the academic's intention and thus actual behavior to share their knowledge. Such factors may differ between public and private universities. The result in is different with Babalhavaeji and Kermani's (2011) findings that revealed no significant relationship between knowledge sharing behavior of faculty members working in government and private universities. This research has also proposed a model of the factors that may affect knowledge sharing behavior among academics in UAE universities. The results showed that all except one of the hypotheses have been supported, where it has been found that academics' intention has a significant influence on knowledge sharing behavior and is the main determinant of their behavior (path coefficient $=0.518$, t-statistics $=7.170$ ). This result is consistent with the theory of planned behavior and of previous studies (Alajmi, 2011; Chen et al., 2009; Tohidinia and Mosakhani, 2010). Intention to share knowledge explained $27 \%$ of the variance in knowledge sharing behavior.

Moreover, the results showed that attitude has a significant influence on intention (path coefficient $=$ 0.338 , t-statistics $=4.752$ ), subjective norms has a significant influence on intention (path coefficient $=$ 0.314 , t-statistics $=3.169$ ), and self-efficacy has significant influence on intention (path coefficient $=$ 0.276 , $t$-statistics $=2.056$ ). Therefore, $\mathrm{H} 1-\mathrm{H} 4$ are supported. These results are consistent with prior research findings on knowledge sharing behavior (Babalhavaeji \& Kermani, 2011, Bock et al., 2005; Chen et al., 2009; Chennamaneni, 2006; Ellahi \& Mushtaq, 2011; He-feng, 2009; Hung et al., 2010 ; Lin, 2007; Lin \& Lee, 2004; Ryu et al., 2003; Tohidinia \& Mosakhani, 2010; Seba et al., 2012). Collectively, attitude towards knowledge sharing, subjective norms, and self-efficacy explained more than $47 \%$ of the variance in intention. Nevertheless, contradictory to previous researches, the results showed that controllability does not have significant influence on academic's intention (path coefficient $=-0.139$, $t$-statistics $=1.421$ ). This could be attributed to that individuals' intention to perform or not perform certain behavior depends somehow on non-motivational factors as availability of requisite opportunities and resources (Ajzen, 1991). These opportunities and resources, i.e. certain factors, represent the individuals' actual control 
over the behavior. However, this result is consistent with Alajmi's $(2010,2011)$ findings on the influence of TPB determinants on individuals' knowledge sharing behavior in an online community, where she found that controllability had no significant influence on intention. Although the results of the current research are in consistency with those of previous studies, the findings of the current research make a good contribution to the literature of knowledge sharing where it addresses particularly knowledge sharing behavior and academics' behavior. Reviewing previous researches, it is noticed that they either studied intention to share knowledge or knowledge sharing, while the few that have actually studied knowledge sharing behavior either targeted employees and managers or were conducted in different contexts.

\section{Conclusion}

This research makes a valuable contribution given the dearth of empirical studies on knowledge sharing in the Arab world. It has studied the influence of some factors on academics' knowledge sharing behavior in UAE universities adopting the TPB. As such, it makes an essential contribution to the investigation of knowledge sharing behavior in a new context in the Arab world. It has also studied it in a non-addressed sector, which is the higher education sector. Moreover, this research is expected to help decision makers in higher education in UAE and Arab world with a reason to encourage knowledge sharing. This would promote collaboration and exploit existing knowledge to enhance performance and sustain competitiveness. In addition, academics themselves would feel encouraged to create and share knowledge by conducting more researches and scientific studies and by publishing scholarly works as well as by exchanging their knowledge and expertise. A better understanding of the importance of knowledge sharing is quite fundamental for the workflow and workforce of all types of organizations regardless of the service they provide. The importance of knowledge sharing should be more obvious to higher education institutions than other organizations since knowledge creation, exchange, and utilization is the core of their work and to their academics in particular, due to their deep-rooted role in higher education that views them as knowledge creators. Therefore, it is important for higher education institutions to develop and harness an appropriate environment that facilitate knowledge sharing. If UAE is to build a knowledge-based society in the region, then it has to promote a culture of knowledge sharing.

Recommendations: Based on the findings of this research, the researcher suggests some recommendations for future research including:

- $\quad$ Examining in depth the influence of other individual factors on knowledge sharing such as reciprocal benefits, enjoyment in helping others, professional enhancement, peers' influence, and loss of knowledge power.

- Exploring the influence of various organizational and technological factors such as organizational culture, leadership, rewards, availability of ICT, technical support, knowledge management systems.

- With the existence of people from different cultures in the Arab World, more research is required to explore the influence of cultural attributes on knowledge sharing behavior.

- $\quad$ Replicating the current research in other countries in the Arab world and in different sectors is essential to yield comparable results and explore knowledge sharing process and its related aspects in the Arab world.

- $\quad$ Using some qualitative research methods such as interviews, case studies, and longitudinal studies would be very useful to develop a deeper understanding of knowledge sharing in academic institutions.

\section{References}

Abdi, H. (2003). Partial Least Squares (PLS) Regression, Lewis-Beck M, Bryman A, Futing T (Eds.), Encyclopedia of Social Sciences Research Methods. Thousand Oaks, California, 1-7.

Ahmad, N. \& Daghfous, A. (2010). Knowledge sharing through inter-organizational knowledge networks: Challenges and opportunities in the United Arab Emirates. European Business Review, 22(2), 153174.

Ajzen, I. (1985). From intentions to actions: A theory of planned behavior. In J. Kuhl \& J. Beckman (eds.), Action control: From cognition to behavior (pp. 11-39). Berlin: Springer-Verlag.

Ajzen, I. (1991). The theory of planned behavior. Organizational behavior and human decision processes, $50,179-211$. 
Ajzen, I. (2002). Perceived behavioral control, self-efficacy, locus of control, and the theory of planned behavior. Journal of Applied Social Psychology, 32(4), 665-683.

Ajzen, I. (2006). Constructing a theory of planned behavior questionnaire. Retrieved December 1, 2012. http://people.umass.edu/aizen/pdf/tpb.measurement.pdf

Alajmi, B. M. (2010). The intention to share: Psychological investigation of knowledge sharing behavior in online communities. Retrieved $\quad$ February $1, \quad 12$. http://tappedin.org/tappedin/web/papers/2011/Bibi-IntentionToShare2011.pdf

Alajmi, B. M. (2011). The intention to share: Professionals' knowledge sharing behaviors in online communities. Doctoral thesis, The State University of New Jersey. Retrieved February 1, 2012. www.tappedin.org/publications/2011/Bibi-IntentionToShare2011.pdf

Alavi, M. \& Leidner, D. (2001). Knowledge management and knowledge management systems: Conceptual foundations and research issues. MIS Quarterly, 25(1), 107- 136.

Al-Nahyan, N. B. M. (2012). Executive focus: Government commitment and investment in education, research initiatives, and improving the quality of education. Retrieved June 6, 2012. http://www.theprospectgroup.com/executivefocus/profile/h-h-sheikh-nahyan-bin-mubarak-alnahyan-minister-of-higher-education-and-scientific-research-uae-2/8578

Alrawi, K. \& Jaber, K. H. (2007). Virtual classrooms and the flexibility of e-learning in the Gulf universities. Journal of knowledge Management Practice, 8(3).

Aulawi, H., Sudirman, I., Suryadi, K. \& Govindaraju, R. (2009). Knowledge sharing behavior, antecedents and their impact on the individual innovation capability. Journal of Applied Sciences Research, 5(12), 2238-2245.

Babalhaveji, F. \& Kermani, Z. J. (2011). Knowledge sharing behavior influences: A case of library and information science faculties in Iran. Malaysian Journal of Library \& Information Science, 16(1), 114.

Basu, B. \& Sengupta, K. (2007). Accessing Success Factors of Knowledge Management Initiatives of Academic Institutions - a Case of an Indian Business School. Retrieved January 6, 2013. www.ejkm.com/issue/download.html?idArticle=111

Bock, G. W. \& Kim, Y. G. (2002). Breaking the myths of rewards: An exploratory study of attitude about knowledge sharing. In PACIS Proceedings.

Bock, G. W., Zmud, R. W., Kim, Y. G. \& Lee, J. N. (2005). Behavioral intention formation in knowledge sharing: Examining the roles of extrinsic motivators, social-psychological forces, and organizational climate. MIS Quarterly, 29(1), 87-111.

Bordia, P., Irmer, B. E., Garden, M., Phair, K. \& Abusah, D. (2004). Knowledge sharing in response to a supportive work environment: evidence from an Australian engineering firm.

Boumarafi, B. M. (2006). Knowledge management and performance in business organizations: an exploratory study in United Arab Emirates. Retrieved January 17, 2011. www.ipac.kacst.edu.sa/eDoc/2007/165431_1.pdf

Chatzoglue, P. D. \& Vraimaki, E. (2009). Knowledge sharing behavior of bank employees in Greece. Business Process Management Journal, 15(2), 245-266.

Chen, I. Y., Chen, N. S. \& Kinshuk, K. (2009). Examining the factors influencing participants' knowledge sharing behavior in virtual learning communities. Educational Technology \& Society, 12(1), 134148.

Cheng, M. Y., Ho, J. S. \& Lau, P. M. (2009). Knowledge sharing in academic institutions: A study of Multimedia University Malaysia. Electronic Journal of Knowledge Management, 7(3), 313-324.

Chennamaneni, A. (2006). Determinants of knowledge sharing behaviors: Developing and testing an integrated theoretical model. Doctoral dissertation. The University of Texas at Arlington.

Chin, W. W. (1998). The partial least squares approach for structural equation modeling, modern methods for business research. London: Lawrence.

Constant, D., Kiesler, S. \& Sproull, L. (1994). What's mine is ours, or is it? A study of attitudes about information sharing. Information Systems Research, 5(4) 400-421.

Egger, U. K. (2013). Cross-organizational knowledge sharing.

Ellahi, A. A. \& Mushtaq, R. (2011). Probing factors affecting knowledge sharing behavior of Pakistani bloggers. Electronic Journal on Information Systems in Developing Countries, 45(6), 1-14.

Fornell, C. \& Larcker, D. (1981). Evaluating structural equation models with unobservable variables and measurement error. Journal of Marketing Research, 18, 39-50.

Fullwood, R., Rowley, J. \& Delbridge, R. (2013). Knowledge sharing amongst academics in UK universities. Journal of Knowledge Management, 17(1), 123-136.

Gay, L. \& Airasian, P. (2003). Educational research: Competencies for analysis and applications. Upper Saddle River, NJ. : Pearson Education. 
Gera, R. (2012). Bridging the gap in knowledge transfer between academia and practitioners. International Journal of Educational Management, 26(3), 252-273

Hair, J. F., Ringle, C. M. \& Sarstedt, M. (2011). PLS-SEM: Indeed a silver bullet. Journal of Marketing Theory and Practice, 19(2), 139-151

Hansmann, K. W. \& Ringle, C. M. (2004). SmartPLS manual, institute for operations management and organizations. Universität Hamburg, Germany.

He-feng, X. (2009). The determinations of employee's knowledge sharing behavior: An empirical study based on the theory of planned behavior. Paper presented at International Conference on Management Science \& Engineering (16th) September 14-16, 2009, Moscow. Retrieved February 17, 2012. http://ieeexplore.ieee.org/stamp/stamp.jsp?tp=\&arnumber=5318075

Henderson, K. (2005). The knowledge sharing approach of the United Nations Development Program. Knowledge Management for Development Journal, 1(2), 19-30.

Hsu, I. (2008). Knowledge sharing practices as facilitating factor for improving organizational performance through human capital: A preliminary study. Experts Systems with Applications, 35, 1316-1326.

Hsu, M. H., Ju, T. L., Yen, C. H. \& Chang, C. M. (2007). Knowledge sharing behavior in virtual communities: The relationship between trust, self-efficacy, and outcome expectations. International Journal of Human-Computer Studies, 65, 153-169.

Hung, S. Y., Lai, H. M. \& Chou, Y. C. (2010). The determinants of knowledge sharing intention in professional virtual communities: An integrative model. Paper presented at the 14th Pacific Asia Conference in Information Systems, July 9-12, 2010, Taipei, Taiwan.

Kamal, K. J., Singh S. M. \& Kaur, S. G. (2007). Knowledge sharing among academic staff: A case study of business schools in Klang Valley, Malaysia. JASA, 2, 23-28.

Ketvirtis, S. (2011). Knowledge sharing: Leveraging trust and leadership to increase team performance. Retrieved March 16, 2013, http://www.sesp.northwestern.edu/msloc/knowledgelens/stories/2012/knowledge-sharing-leveraging-trust-and-leadership-to-increase-teamperformance.html

Kenett, R. S. \& Rahav, E. (2006). Bootstrap Analysis of Designed Experiments. Quality and Reliability Engineering International, 22(6), 659 - 667.

Keyes, J. (2008). Identifying the Barriers to Knowledge Sharing in Knowledge Intensive Organizations. Doctoral dissertation, North Central University.

Kijsanayotin, B., Pannarunothai, S. \& Speedie, S. M. (2009). Factors influencing health information technology adoption in Thailand's community health centers: Applying the UTAUT model. International journal of medical informatics, 78(6), 404-16. doi:10.1016/i.ijmedinf.2008.12.005

Kraft, P., Rise, J., Sutton, S. \& Roysamb, E. (2005). Perceived difficulty in the theory of planned behavior: Perceived behavioral control or affective attitude? British Journal of Social Psychology, 44, 479496.

Lin, H. F. (2007). Effects of extrinsic and intrinsic motivation on employee knowledge sharing intentions. Journal of Information Science, 33(2), 135-149.

Lin, H. F. \& Lee, G. G. (2004). Perceptions of senior managers toward knowledge sharing behavior. Journal of Management Decision, 42(1), 108-125.

Ling, C. W., Sandhu, M. S. \& Kamal, K. J. (2009). Knowledge sharing in an American multinational company based in Malaysia. Journal of Workplace Learning, 21(2), 125-142.

Madden, T. J., Ellen, P. S. \& Ajzen, I. (1992). A comparison of the theory of planned behavior and the theory of reasoned action. Personality and Social Psychology Bulletin, 18(1), 3-9.

Mazzarol, T. \& Soutar, G. N. (2002). The Global market for higher education: Sustainable competitive strategies for the new millennium. Cheltenham, UK: Edward Elgar Publishing Ltd.

Metcalfe, A. S. (2006). Knowledge management and higher education: A critical analysis. Hershey, PA: Information Science Publishing.

Mirghani, M., O’Sullivan, K. J. \& Ribie`re, V. (2008). A paradigm shift in the Arab region knowledge evolution. Journal of Knowledge Management, 12(5), 107-120.

Moshabbaki, A. \& Jaha'nyan, S. (2009). A Trust-based model for knowledge sharing in ERP adopting organizations. Journal of Knowledge Management Practice, 10(1). Retrieved January 23, 2012. http://www.tlainc.com/articl176.htm

Nonaka, I. \& Takeuchi, H. (1995). The knowledge-creating company: How Japanese companies create the dynamics of innovation. Oxford: Oxford University Press.

Patel, M. \& Ragsdell, G. (2011). To share or not to share: An ethical dilemma for UK academics? Journal of Knowledge Management Practice, 12(2). 
Riege, A. (2005). Three-dozen knowledge-sharing barriers managers should consider. Journal of Knowledge Management, 9(3), 18-35.

Rijlaarsdam, R. (2007). The interaction effect of source and motives on fairness perceptions in the context of revenue management in the airline industry. Master thesis, Unverisiteit Maastricht

Robertson, S. (2002). A tale of two knowledge-sharing systems. Journal of Knowledge Management, 6(3), 295-308.

Rowley, J., Seba, I. \& Delbridge, R. (2012). Knowledge sharing in the Dubai Police Force. Journal of Knowledge Management, 16(1), 1-24.

Ryu, S., Ho, S. H. \& Han, I. (2003). Knowledge sharing behavior of physicians in hospitals. Expert Systems with Application, 25, 113-122.

Sallis, E. \& Jones, G. (2002). Knowledge Management in Education: Enhancing learning and education. London: Kogan Page.

Sandhawalia, B. S. \& Dalcher, D. (2011). Effective knowledge sharing for competitive advantage. Journal of Knowledge Management, 15(2).

Schilling, D. R. (2013). Knowledge doubling every 12 months, soon to be every 12 hours. Retrieved November 21, 2013.http://www.industrytap.com/knowledge-doubling-every-12-months-soonto-be-every-12-hours/3950

Seba, I., Rowley, J. \& Lambert, S. (2012). Factors affecting attitudes and intentions towards knowledge sharing in the Dubai Police Force. International Journal of Information Management, 1120, 1-9. Retrieved January 27, 2012. www.sciencedirect.com/science/article/pii/S0268401211001563

Sharma, A. (2010). Enabling knowledge management of organizational memory for groups through shared topic maps. Master dissertation. Iowa State University.

Singer, P. \& Hurley, J. E. (2005). The Importance of Knowledge Management Today. ALA-APA Library Worklife Home, 2(6), 1-3.

Skok, W. \& Tahir, S. (2010). Developing a knowledge management strategy for the Arab World. Electronic Journal on Information Systems in Developing Countries, 41(7), 1-11.

So, J. \& Bolloju, N. (2005). Explaining the intentions to share and reuse knowledge in the context of IT service operations. Journal of Knowledge Management, 9(6), 30-41.

Sohail, S. \& Daud, S. (2009). Knowledge sharing in higher education institutions: Perspectives from Malaysia. The Journal of Information and Knowledge Management Systems, 39(2), 125-142.

Srivastava, A., Bartol, K. M. \& Locke, E. A. (2006). Empowering leadership in management teams: Effects on knowledge sharing, efficacy, and performance. Academy of Management Journal, 49(6), 12391251.

Syed, S. A., Zaini, A., Noormala, A. I. \& Zahariah, M. Z. (2009). Assessing knowledge sharing behavior among employees in SMEs: An empirical study. International Business Research, 2(2), 115- 122.

Tan, C. N., Lye, Y. H., Ng, T. H. \& Lim, Y. S. (2010). Motivational factors in influencing knowledge sharing among banks in Malaysia. International Research Journal of Finance and Economics, 44, 191-201.

Tavousi, M., Hidarnia, A. R., Montazeri, A., Hijizadeh, E., Taremain, F. \& Ghofranipour, F. (2009). Are perceived behavioral control and self-efficacy distinct constructs? European Journal of Scientific Research, 30(1), 146-152.

Taylor, S. \& Todd, P. A. (1995). Understanding information technology usage: a test of competing models. Information Systems Research, 6(2), 144-76.

Tohidinia, Z. \& Mosakhani, M. (2010). Knowledge sharing behavior and its predictors. Industrial Management \& Data Systems, 110(4), 611-631.

Trafimow, D., Sheeran, P., Conner, M. \& FInaly, K. A. (2002). Evidence that perceived behavioral control is a multidimensional construct: Perceived control and perceived difficulty. British Journal of Social Psychology, 41, 101-121.

Wang, S. \& Noe, R. (2010). Knowledge sharing: A review and directions for future research. Human Resource Management Review, 20, 115-131.

Wasko, M. M. \& Faraj, S. (2005). Why should I share? Examining social capital and knowledge contribution in electronic networks of practice. MIS Quarterly, 29(1), 35-57.

Weir, D. \& Hutchings, K. (2005). Cultural embeddedness and contextual Constraints: Knowledge Sharing in Chinese and Arab Cultures. Knowledge and Process Management, 12(2), 88-98.

Xiao, Y. C. \& Jin, Y. H. (2010). The hierarchical linear modeling of shared mental model on virtual team effectiveness. Kybernetes, 39(8), 1322-1329.

Ye, S., Chen, H. \& Jin, X. (2006). An empirical study of what drives users to share knowledge in virtual communities, in J. Lang, F. Lin \& J. Wang (Eds.), Knowledge science, engineering and management: First international conference, KSEM 2006, Springer-Verlag Berlin Heidelberg, (pp. 563-575). 